\title{
Práticas de letramento docente no estágio supervisionado de letras estrangeiras
}

\section{Teacher literacy practices in the foreign letters supervised internship}

Carla Lynn Reichmann*

Universidade Federal da Paraíba

João Pessoa - Paraíba / Brasil

RESUMO: Neste artigo discuto a relevância de práticas de letramento no estágio. Alinhando-me aos novos estudos de letramento (BARTON et al., 2000) e considerando a escrita como elemento identitário de formaçāo (KLEIMAN, 2007), adoto a perspectiva bakhtiniana de gênero a fim de investigar relatos autobiográficos alicerçados em fotobiografias escolares produzidas em uma disciplina de estágio em língua estrangeira, em 2011. Neste recorte analiso as vozes enunciativas que ecoam em dois relatos, em especial as vozes de personagem e autor (BRONCKART, 1999; 2006), para sintonizar com as vozes e identidades sociais que se constituem nos textos. Em suma, retomando Kleiman $(2006 ; 2011)$, saliento o impacto vital do trabalho do professor como agente de letramento, levando em conta a heterogeneidade das trajetórias de letramento e formação.

PALAVRAS-CHAVE: letramento docente, gênero profissional, vozes, estágio, Letras.

ABSTRACT: In this article I discuss the relevance of teacher literacy practices in teaching internship. In line with the new literacy studies (BARTON et al., 2000), and considering writing as an identity element in teacher education (KLEIMAN, 2007), I adopt a bakhtinian perspective on genre in order to investigate autobiographical papers triggered by photobiographies produced in a Foreign Letters undergraduate program in Northeast Brazil, in 2011. In this study, I will analyze the voices that echo in two reflective papers, especially character and author voices (BRONCKART, 1999; 2006), so as to attune to the voices and social identities construed in text. In sum, along Kleiman's words $(2006 ; 2011)$, this study highlights the vital impact of the teacher positioned as a literacy agent, taking into account the heterogeneity of teacher literacy and development trajectories.

KEYWORDS: teacher literacy, professional genre, voice, internship, Letters.

* carlareichmann@hotmail.com 
As palavras são tecidas a partir de uma multidão de fios ideológicos e servem de trama a todas as relaçôes sociais em todos os domínios

\section{Introdução}

Situado na Linguística Aplicada, este artigo $^{1}$ tem como objetivo geral refletir sobre práticas de letramento e formação identitária em uma licenciatura em Letras Estrangeiras. Neste recorte focalizo um momento inicial no estágio supervisionado, atenta à seguinte questão norteadora: quais as principais vozes enunciativas (BRONCKART 1999; 2006) que emergem em relatos autobiográficos desencadeados por fotobiografias escolares - e o que dizem sobre si e sobre a escola? Vale salientar que esta discussão sobre letramento, identidade e gênero profissional no âmbito do ensino superior leva em conta o relato autobiográfico como prática de letramento, envolvendo ações de linguagem permeadas por memórias individuais e sociais de professores em formação prestes a mergulhar na fase de intervenção da prática de ensino de língua estrangeira. Outras práticas de letramento, tais como portfólios, planos de aula, blog e relatório de estágio também foram realizadas ao longo da disciplina, ministrada em uma universidade pública no nordeste, em 2011.

Adotando um olhar bakhtiniano ao sublinhar que circulamos por vários gêneros, Clot (2007, p. 188-189), situado no campo das Ciências do Trabalho, frisa que "o repertório genérico de um sujeito pode ultrapassar o repertório do gênero da situação em que ele trabalha. O sujeito não vive no interior de um único gênero". Clot também afirma "que as pertinências múltiplas - diríamos, as atividades plurigenéricas - constituem uma das principais fontes das criações estilísticas" (CLOT, 2007, p. 189). Diante disso, proponho que ao entrelaçar o gênero relato autobiográfico ao gênero profissional docente, possibilita-se vislumbrar as delicadas teias dialógicas urdidas pelos mundos da escola, da formação, do trabalho e da linguagem; ao imaginar e tecer com palavras as diversas esferas do mundo da vida, espero possibilitar estilos e gêneros profissionais renovados, pois como nos lembra Jean Paul Bronckart "o desenvolvimento humano nada mais é, de fato, que o movimento permanente

\footnotetext{
${ }^{1}$ Versão expandida da comunicação apresentada no VI Simpósio Internacional de Estudos dos Gêneros Textuais (Siget), integrada ao simpósio temático "Letramento do professor e gêneros textuais: demandas, dificuldades e possibilidades", sob coordenação da Profa. Dra. Angela Kleiman e da Profa. Dra. Maria do Socorro Oliveira.
} 
de atribuição de significações a nosso agir e a nossa vida" (BRONCKART, 2008, p. 183). Nesses termos, situado no campo transdisciplinar da Linguística Aplicada e buscando revitalizar o gênero profissional, este trabalho se insere nas discussōes sobre o agir docente do Grupo de Estudos de Letramentos, Interação e Trabalho (Gelit/UFPB) e do Grupo de Pesquisa Letramento do Professor (Unicamp), ambos cadastrados no CNPq, como também se insere nas discussões do subGT de Formação de Professores vinculado ao GT de Linguística Aplicada da Anpoll.

Uma questão basilar, como lembra Carlos A. Faraco, é a crítica bakhtiniana em relação à separação abstrata entre o mundo da cognição e o mundo da vida: como professores, nos deparamos com um imenso desafio ao buscarmos "romper com o teoreticismo em nossas práticas e obter o envolvimento existencial dos nossos educandos (como pessoas concretas) na experiência de ser autor e de ser leitor ativamente partícipe do vasto diálogo cultural" (FARACO, 2007, p. 50). Nessa linha de raciocínio, alinhando-se a Michael Connelly e Jean Clandinin (1999) e Tânia Regina de S. Romero (2008), ao focalizarmos histórias de vida e representarmos a nossa experiência em texto, criamos um instigante desafio, como salienta Freema ElbazLuwisch, "aberto a revisões e questionamentos constantes; e nesse processo, nós não só revisamos o texto, como também o próprio texto pode forjar novas experiências" (ELBAZ-LUWISCH, 2005, p. 38). Reafirmando a importância de práticas de letramento e formação socioprofissional ancoradas em experiências de vida, Marie-Christine Josso (2004), consoante com António Nóvoa (1992), assevera que tais narrativas de formação engendram singulares metaterritórios do imaginário.

É importante ressaltar que o presente estudo problematiza histórias e trajetórias socioprofissionais alicerçadas na perspectiva de letramento como um conjunto de práticas sociais, considerando que "os significados específicos que a escrita assume por um grupo social dependem dos contextos e instituiçôes em que ela foi adquirida" (KLEIMAN, 1995, p. 21); a escrita é vista como uma prática situada, baseada em situaçóes reais (BARTON et al., 2000). Daí decorre a noção da escola como agência de letramento (entre inúmeras outras possíveis, tais como família, igreja, associação de bairro, sindicato, por exemplo) e do professor como agente de letramento, ou seja, "a representação do professor como agente de letramento põe em relevo a agência humana, a agência institucional e a prática situada da escrita, três elementos relevantes para a construção identitária que decorre do processo de socialização profissional" (KLEIMAN, 2006, p. 90). 
Em suma, considerando o relato autobiográfico como prática de letramento docente e buscando o envolvimento existencial dos formandos, retomo outra questão basilar permeando este trabalho, a saber, a noção da construção social de identidade profissional do professor de línguas como sendo constituída na "discursividade de vozes que ecoam em torno do aluno" (BOHN, 2004, p. 97); ou ainda, como sugiro ao longo do presente artigo, na distribuição de vozes de outros (interiorizadas) e de si (internas) que ecoam em textos produzidos por professores em formação. Gostaria de salientar que as referidas vozes sintonizam de alguma forma com um dado contexto de produção (que baliza os parâmetros textuais, como nos ensina Bronckart [1999; 2006], entre outros): ora dissonantes e instáveis, provisoriamente as vozes se afinam, (des)estabilizando construçôes identitárias. E na vida contemporânea, como aponta Moita Lopes (2009), a questão da identidade social perpassa todas as Ciências Humanas e Sociais: ancorada na linguagem, a identidade é entendida como descentrada, instável, provisória; é relacional e situada, como nos ensina Claude Dubar (2005), Stuart Hall (2003) e Zymunt Bauman (2005), entre outros. Enfim, este estudo se alinha à definição de identidade segundo Angela B. Kleiman, entendida como "um conjunto de elementos dinâmicos e múltiplos da realidade subjetiva e social, uma condição transitória, moldada pelas relações sociais que, na percepção dos participantes, estão sendo construídas na interação" (KLEIMAN, 1998, citada por VÓVIO; DE GRANDE, 2010, p. 55).

Nessa perspectiva, em relação à questão das vozes e identidade do professor de línguas, cabe mencionar os trabalhos de Hilário I. Bohn (2004), Jane Q. Guimarães Silva e Maria de Lourdes M. Matêncio (2005), Eveline M. TápiasOliveira (2006), Cristina Mott-Fernandez e Vera Lúcia L. Cristóvão (2008), Cláudia L. Vóvio e Paula B. De Grande (2010), como também as recentes pesquisas de doutorado, alicerçadas no interacionismo sociodiscursivo, focalizando o trabalho do professor em contexto de estágio supervisionado de Letras, tais como os trabalhos de Luzia Bueno (2007), Maria Anunciada N. Rodrigues (2011) e Lídia Stutz (2011). Também vale ressaltar a importância de recentes produções de doutorandas no Gelit/UFPB trabalhando com vozes no contexto de formação de professores de língua inglesa, tais como Mariana Pérez (2009), Márcia de A. Pereira (2011) e Sandra Maria A. Dias (não publicado).

Como será visto na próxima seção, serão delineadas as principais opções teórico-metodológicas sustentando esta pesquisa-ação de natureza qualitativa e interpretativa (DENZIN; LINCOLN, 2007), a saber, os novos estudos do 
letramento (BARTON et al. [2000] KLEIMAN; MATÊNCIO [2005]; KLEIMAN [2007]; OLIVEIRA; KLEIMAN [2008]; OLIVEIRA [2010]), dialogismo (BAKHTIN [2010]; BAKHTIN; VOLOSHINOV [1999]) e distribuição de vozes (BRONCKART, 1999; 2006; 2008). A seção seguinte apresenta o contexto de produção dos relatos, os resultados e a discussão focalizando oito fragmentos selecionados de dois relatos autobiográficos, produzidos em 2011 por graduandos em língua inglesa, doravante Ana e João (nomes fictícios). É importante esclarecer que as permissões para a discussão dos dados neste trabalho foram devidamente dadas pelos participantes. Por fim, respondendo à questão inicial, apresentaremos algumas reflexões em construção.

\section{Ancoragem teórico-metodológica}

Inicialmente, apresento um breve panorama das opçóes que sustentam este estudo, a saber, práticas de letramento, dialogismo e distribuição de vozes. Retomando o conceito adotado neste trabalho para letramento, este é entendido como prática social, consoante com a visão de letramento ideológico postulada por Street (1984, ecoando SCRIBNER e COLE [1981] e HEATH [1983]). Filiados à perspectiva de Street (1993), Barton e Hamilton (2000, p. 8) afirmam que por letramento entende-se um conjunto de práticas sociais, historicamente situadas: segundo Street, "práticas de letramento, portanto, referem-se à ampla concepção cultural sobre as maneiras particulares de se pensar sobre e fazer leitura e escrita em contextos culturais" (STREET, 2003, p. 79). Nesses termos, é relevante a concepção de letramento "enquanto conjunto de práticas sociais, cujos modos específicos de funcionamento têm implicações importantes para as formas pelas quais sujeitos envolvidos nessas práticas constroem relaçôes de identidade e poder" (KLEIMAN, 1995, p. 11).

Em outras palavras, neste trabalho é central a visão de que a escrita se constitui como importante elemento identitário de formação (KLEIMAN, 2007), como também a perspectiva sócio-histórica da linguagem: é fulcral a noção bakhtiniana sobre a palavra, que "penetra literalmente em todas as relações entre indivíduos, nas relaçōes de colaboração, nas de base ideológica, nos encontros fortuitos da vida cotidiana, nas relaçōes de caráter político, etc." (BAKHTIN; VOLOSHINOV, 1999, p. 41). Para o círculo russo, a palavra é entendida como "material semiótico da vida interior, da consciência (discurso interior)" (BAKHTIN; VOLOSHINOV, 1999, p. 37). Alinhando-se à epígrafe, a palavra é vista como construto ideológico, forjando, discursiva e 
semioticamente, consciências e relaçóes sociais: ou seja, como bem lembra Faraco, "a consciência é social de ponta a ponta" (FARACO, 2009, p. 86).

Cabe esclarecer aqui o conceito de gênero profissional: partindo do conceito bakhtiniano de gênero (BAKHTIN, 2010, p. 262), a saber, como tipos relativamente estáveis de enunciados Clot (2007, p. 41), assevera-se que o gênero profissional se constitui

um corpo intermediário entre os sujeitos, um interposto social situado entre eles, por um lado, e entre eles e o objeto de trabalho, por outro. De fato, um gênero sempre vincula entre si os que participam de uma situação, como co-autores que conhecem, compreendem e avaliam essa situação da mesma maneira.

Yves Clot ainda esclarece que o gênero profissional se fundamenta em uma memória coletiva da atividade, podendo "definir-se como o conjunto de atividades mobilizadas por uma situação, convocadas por ela” (CLOT, 2007, p. 44). Simultaneamente, o gênero pode renovar-se, pois "[o] gênero modela a situação e esta, em contrapartida, remodela o gênero" (CLOT, 2007, p. 186). Nessa linha de raciocínio, ao nos apropriarmos dos gêneros, podemos 'retocálos', desenvolvendo nosso estilo próprio. Vale mencionar que na minha própria trajetória socioprofissional, envolvendo um número crescente de práticas de letramento e vozes enunciativas, fui me apropriando de diversos gêneros textuais constituindo o gênero profissional docente, ${ }^{2}$ paulatinamente compreendendo seu caráter inacabado - como na vida.

Em suma, adotando a perspectiva do letramento situado e do caráter sócio-histórico da linguagem, este trabalho também se ancora no interacionismo sociodiscursivo (BRONCKART [1999]; MACHADO [2004]; MACHADO; LOUSADA; FERREIRA [2011]), ${ }^{3}$ ao considerar a centralidade da linguagem para a ciência do humano, tendo como instrumentos principais do desenvolvimento humano as práticas linguageiras situadas (os textos) (BRONCKART, 1999). Focalizo os mecanismos enunciativos do texto, em

\footnotetext{
${ }^{2}$ Por exemplo, em relação ao trabalho no ensino superior: aulas, avaliações, bancas, comunicações acadêmicas, consultorias, coordenações, declarações, organizações de eventos, orientações, pareceres, projetos de pesquisa, recursos, representaçóes, reuniōes departamentais, solicitações, entre outros.

${ }^{3}$ E no âmbito do Gelit, Regina C. Pereira (2009), Betânia P. de Medrado (2011) e Carla L. Reichmann (2011).
} 
especial, as vozes enunciativas (BRONCKART, 1999; 2006), a fim de verificar quem diz, vê e pensa o quê (os pontos de vista) nos textos em questão. Retomando a noção bakhtiniana de vozes sociais e de que viver é constantemente se posicionar frente a valores (FARACO, 2007), Bronckart assevera que as vozes "podem ser definidas como as entidades que assumem (ou às quais são atribuídas) a responsabilidade do que é enunciado" (BRONCKART, 1999, p. 326). Em outras palavras, as vozes inscrevem as instâncias enunciativas, assumindo a responsabilidade pelo que é dito (ou pensado). No nível da coerência pragmática no folhado textual, constituem uma categoria relativa aos mecanismos de responsabilização enunciativa, relacionados à interação entre o produtor do texto e os destinatários.

Conforme os tipos de discurso, Bronckart primeiramente sinaliza a constituição de uma voz neutra (de narrador ou expositor); em seguida, esclarece a constituição de outras vozes (infraordenadas em relação ao narrador/ expositor), ${ }_{4}^{4}$ subdivididas em três categorias gerais: vozes de personagens, vozes sociais e voz de autor empírico do texto. Vale esclarecer que as vozes de personagens são entendidas como as vozes advindas de seres humanos (ou de entidades humanizadas) implicados nos acontecimentos do conteúdo temático de um segmento do texto (BRONCKART, 1999, p. 326, 327); as vozes sociais procedem de personagens, grupos ou instituições sociais, não intervindo como agentes no percurso temático, mas mencionadas como instâncias externas de avaliação; a voz do autor "procede diretamente da pessoa que está na origem da produção textual e que intervém, como tal, para comentar ou avaliar alguns aspectos do que é enunciado". Como esclarece Bronckart, "essas vozes podem não ser traduzidas por marcas linguísticas específicas, podem também ser explicitadas por formas pronominais, sintagmas nominais ou, ainda, por frases ou segmentos de frases" (BRONCKART, 1999, p. 149). Nesta discussão, sintonizo em especial com as vozes de personagens e de autor inscritas nos textos dos graduandos sobre suas trajetórias; as vozes sociais, também presentes, ficam para uma futura discussão.

No caso dos relatos autobiográficos desencadeados por fotobiografias, considero aqui as vozes de personagens como sendo constituídas pelas vozes advindas do passado ou do futuro, isto é, convocadas nas lembranças do tempo escolar ou na imaginação sobre o trabalho docente por vir; e como voz de autor, destaco a saliência da voz oriunda do presente compartilhado, em uma

${ }^{4}$ Ver Bronckart (1999) para explicações mais detalhadas. 
comunidade de prática situada na disciplina de estágio. ${ }^{5}$ Dito de outra forma, investigarei as vozes (de personagens e de autor) ecoando nos textos produzidos após a visita à própria escola, a realização das fotobiografias e posterior partilha das fotos em sala de aula. Como será visto na próxima seção, após a descrição das condições de produção dos relatos, serão analisadas as vozes inscritas nesta prática de letramento singular, engendrada na disciplina Estágio Supervisionado VI, da nova matriz curricular dos cursos de licenciatura de Letras Estrangeiras na UFPB. ${ }^{6}$

\section{Vozes enunciativas}

\section{Contexto de produção dos relatos autobiográficos}

Lembrando as palavras de Menga Lüdke (2009), gostaria de reiterar que o estágio é visto como o ponto nevrálgico na formação e concordamos com Stutz (2011), ressaltando que a disciplina de estágio apresenta inúmeros desafios: apesar da complexidade e amplitude que o estágio demanda, há um menor prestígio atribuído à disciplina e aos protagonistas formadores, sinalizando o abismo entre as disciplinas teóricas e as práticas de ensino.

Em 2007, com a nova matriz curricular no curso de Letras da UFPB, os estágios passaram a ser responsabilidade do curso de Letras; em 2011, na disciplina de Estágio Supervisionado VI, visando promover práticas de letramento situado, foi proposto aos graduandos no módulo inicial da disciplina (isto é, antes da entrada nas aulas de língua inglesa na escola-campo), que eles realizassem fotobiografias nas próprias escolas onde haviam estudado, para dessa forma mobilizarem um conjunto de atividades e histórias de vida, posteriormente partilhando as fotos em uma sessão coletiva com os colegas e produzindo um relato autobiográfico documentando a experiência vivida.

De acordo com Bronckart, "o contexto de produção pode ser definido como o conjunto dos parâmetros que podem exercer uma influência sobre a

\footnotetext{
${ }^{5}$ Faraco reitera que o autor "é entendido como uma função interna do texto, como o elemento ordenador da totalidade do sentido do texto" (FARACO, 2007, p. 48); implica em um posicionamento axiológico, valorativo.

${ }^{6}$ Matriz, por sinal, em discussão na Comissão de Estágios e prestes a ser reorganizada. Atualmente há sete estágios, totalizando 420 horas; os Estágios 5, 6 e 7 envolvem intervenção em escolas-campo (no Ensino Fundamental, Médio e em Curso Livre, respectivamente); o Estágio 6 corresponde ao Ensino Médio.
} 
forma como um texto é organizado" (BRONCKART, 1999, p. 93), reunidos em dois grupos, a saber, o mundo físico e o mundo sociossubjetivo. Os parâmetros do mundo físico situam o comportamento verbal concreto de um agente em um espaço-tempo específico; os parâmetros do mundo sociossubjetivo, mais complexos, enquadram a produção textual como uma forma de interação comunicativa, isto é, em relação a lugares e papéis sociais. A fim de sintetizar as condições de produção dos relatos, destaco os mundos físicos e sociossubjetivos no quadro a seguir:

\section{QUADRO 1}

Representações dos mundos físico e sociossubjetivo dos relatos autobiográficos

\begin{tabular}{|c|c|c|c|c|}
\hline & $\begin{array}{c}\text { Lugar } \\
\text { de produção }\end{array}$ & $\begin{array}{l}\text { Momento } \\
\text { de produção }\end{array}$ & Emissor & Receptor \\
\hline \multirow[t]{2}{*}{$\begin{array}{l}\text { Mundo } \\
\text { físico }\end{array}$} & $\begin{array}{l}\text { Residência do/a } \\
\text { estudante }\end{array}$ & $\begin{array}{l}\text { Após a realização } \\
\text { de fotobiografia } \\
\text { e partilha }\end{array}$ & $\begin{array}{l}\text { Graduando no } 6^{\circ} \\
\text { período do curso de } \\
\text { Letras Estrangeiras, } \\
\text { DLEM/UFPB, } \\
2011.1\end{array}$ & $\begin{array}{c}\text { Professora } \\
\text { de Estágio } \\
\text { Supervisionado VI, } \\
\text { DLEM,/UFPB, } \\
2011.1\end{array}$ \\
\hline & $\begin{array}{l}\text { Lugar social } \\
\text { de produção }\end{array}$ & $\begin{array}{c}\text { Objetivo - } \\
\text { propósito } \\
\text { comunicativo }\end{array}$ & $\begin{array}{l}\text { Papel social do } \\
\text { enunciador }\end{array}$ & $\begin{array}{l}\text { Papel social do } \\
\text { destinatário }\end{array}$ \\
\hline $\begin{array}{l}\text { Mundo } \\
\text { sociossubjetivo }\end{array}$ & $\begin{array}{l}\text { Universidade - } \\
\text { contexto } \\
\text { acadêmico }\end{array}$ & $\begin{array}{c}\text { Relatar à } \\
\text { professora de } \\
\text { estágio a história } \\
\text { vivida ao rever a } \\
\text { própria escola } \\
\text { e ao partilhar } \\
\text { fotobiografias na } \\
\text { universidade, a fim } \\
\text { de mobilizar um } \\
\text { conjunto de } \\
\text { situações vividas } \\
\text { antes da entrada } \\
\text { na escola-campo }\end{array}$ & $\begin{array}{l}\text { Acadêmicos do } \\
\text { curso de Letras } \\
\text { Estrangeiras - } \\
\text { língua inglesa que, } \\
\text { após vivência com } \\
\text { fotobiografias, } \\
\text { escrevem sobre } \\
\text { a experiência }\end{array}$ & $\begin{array}{c}\text { Professora de } \\
\text { Estágio } \\
\text { Supervisionado VI } \\
\text { que atua como } \\
\text { professora- } \\
\text { supervisora e } \\
\text { desempenha o } \\
\text { papel de leitora } \\
\text { dos relatos } \\
\text { autobiográficos } \\
\text { no módulo inicial } \\
\text { da disciplina }\end{array}$ \\
\hline
\end{tabular}

Fonte: BRONCKART, 1999, p. 93.

A partilha das doze fotobiografias criou no espaço-tempo da aula um caleidoscópio constituído por diversas imagens de escola: urbana, rural, laica, religiosa, pequena, enorme, sem recursos, high-tech. Certas imagens são recorrentes - pessoas, salas de aula, bibliotecas, pátios, corredores, cantinas, árvores, escadas, muros, grades, janelas; lugares secretos, lugares proibidos, 
lugares que não existem mais (ou seja, somente nas lembranças do sujeito ali posicionado). Imagens, memórias e trajetórias divergentes e convergentes, vozes que dialogam, como será discutido a seguir, através de fragmentos de dois relatos autobiográficos, de Ana e João (dentre um universo de doze relatos), selecionados devido às dramáticas diferenças em relação às vivências em escolas públicas (ver Anexo).

\section{Caminho das pedras, caminho das letras}

Nos relatos de Ana e João foram convocadas vozes de personagens situadas no passado, tanto a voz do outro, interiorizada, a saber, do professor de português e da própria mãe, como também a voz de si, interna, situada no passado, de estudante de Ensino Médio, escritora e vestibulando/universitário; além dessas vozes de personagens, foi identificada a voz de si situada no futuro, como profissional de ensino. É saliente a voz de autor posicionada no presente como professorla em formação, conforme pode ser verificado nos resultados apresentados no quadro a seguir:

\section{QUADRO 2}

Vozes de personagem e de autor empírico (marcado em destaque) nos relatos

\begin{tabular}{|l|c|c|c|}
\hline & $\begin{array}{c}\text { Passado } \\
\text { (na escola) }\end{array}$ & $\begin{array}{c}\text { Presente } \\
\text { (na universidade) }\end{array}$ & $\begin{array}{c}\text { Futuro } \\
\text { (no trabalho) }\end{array}$ \\
\hline $\begin{array}{l}\text { Vozes de outros: } \\
\text { Personagens }\end{array}$ & Professor de português & - & - \\
$\begin{array}{l}\text { Vozes de si: } \\
\text { personagens } \\
\text { e autor }\end{array}$ & $\begin{array}{c}\text { Mãe } \\
\text { Estudante de Ensino Médio }\end{array}$ & $\begin{array}{c}\text { Professorla em } \\
\text { formação }\end{array}$ & Professora profissional \\
\hline
\end{tabular}

Nos fragmentos apresentados adiante, percebe-se que as supracitadas vozes enunciativas discorrem sobre temas relacionados a memórias dos tempos da escola, à visita, à escrita, ao momento de partilha das fotos na universidade, a uma possível situação profissional. Indiciam tensōes que ora sinalizam conflitos, ora constituem ressignificações em singulares histórias de vida de professores. Vale salientar que no relato de Ana verifica-se em diversos momentos um forte componente afetivo em relação à vida escolar e à vida pessoal, como também em relação aos textos que produz(iu) - projeto, teatro, fotobiografia, relato e portfólio. Chama a atenção que as vozes de personagem (de outros), nos relatos de Ana e João, são principalmente vozes de apoio e incentivo. 
Apresento a seguir quatro trechos do relato de João. Estudou em uma escola na periferia da cidade e na partilha das fotos explica, sem dramas, como a barra era pesada, como muitos já se foram. É um sobrevivente, desconstruindo "aquele mito que se ouve tanto na periferia: 'Ah, você não vai conseguir [o vestibular], você fez escola pública...”" (BALLOUSSIER, 2011), como pode ser verificado nos fragmentos a seguir, com grifos meus:

\section{Fragmento 1 (inicial)}

Quando tirei as fotos na visita à escola na qual estudei durante o ensino médio, tive uma breve lembrança do tempo que vivi por lá e pouca coisa me veio à cabeça no tocante à memória escolar, porém no momento em que apresentei à turma, tive uma visão melhor da minha vida escolar e pude compartilhar o que pareceu um pouco diferente dos demais. Achei interessante ressaltar detalhadamente como na verdade funciona o ensino nas escolas públicas, os problemas encontrados nelas, falta de compromisso por parte dos diretores, e todos envolvidos no processo de educação.

\section{Fragmento 2}

Uma das memórias mais marcantes desse período está ligada ao professor $H$, um ex-aluno dessa mesma escola, que dava a melhor aula de português, sempre conscientizando a turma de não deixar de estudar, a fim de obter um futuro melhor.

\section{Fragmento 3}

Mas toda aquela atmosfera caótica por outro lado, me instigava a estudar mais, pois sabia que passar no vestibular não seria algo fácil. Não tenho lembrança de que alguém daquela época, tivesse passado no vestibular.

Fragmento 4 (final)

[...] não é fácil resolver esses problemas porque são os próprios alunos que deterioram a escola, quebram os banheiros e picham as paredes; acho que esses problemas têm relação com a construção de identidade do indivíduo, ou seja, problemas sociais, familiares e que pouco serão resolvidos por educadores. Hoje sei que as pedras encontradas no caminho serviram de montanha, onde eu pude subir e ver a vida através de outra perspectiva.

Podemos verificar no fragmento inicial que é no momento que as vozes dialogam em sala de aula que João toma consciência da singularidade da sua perspectiva; em resposta à voz do outro (“a turma [de estágio em Letras]”), percebe a alteridade, se diferencia e se identifica. Posicionado na disciplina de 
Estágio, esboça um gesto responsivo ativo, dá voz ao professor em formação, a voz de autor, afirmando "achei interessante ressaltar detalhadamente como na verdade funciona" a escola pública (a que vivenciou), retratada como uma instituição sem engajamento que resulta em uma "atmosfera caótica".

A seguir, uma lembrança/voz alheia marcante - o professor $\mathrm{H}$, "ex-aluno [...] que dava a melhor aula de português" (por sinal, neste relato, a única referência ao campo de Letras), dizendo aos alunos para seguirem lutando, sinalizando um futuro diferente. Ou seja, emerge esta voz de personagem, o professor $\mathrm{H}$, incentivando; e no fragmento seguinte, como um sonho, uma luz no fim do túnel, surge o vestibular, na voz do vestibulando/futuro universitário - "não seria algo fácil" e não se lembra de "alguém [...] que tivesse passado". No fragmento final, ouve-se novamente a voz do autor/professor em formação, advinda da academia, falando de construção de identidade do indivíduo, mas sem esperança em relação à escola e aos educadores: os problemas sociais e familiares parecem apontar para além das possibilidades da escola; são insolúveis. No fragmento final ouve-se novamente a voz de autor/ professor em formação: escalou-se o caminho das pedras, vislumbra-se o topo da montanha e, por meio desse reposicionamento, avalia-se que uma nova perspectiva de vida foi engendrada. Constitui-se também um silêncio, pois é inaudível a voz da família ou da escola como agência de letramento; há, sim, uma história heroica, tensa, de superação e sobrevivência.

Enfim, a escola não se constitui como agência de letramento, é uma escola caótica que cala, não dá voz - diferentemente da escola reconfigurada no relato de Ana (ao falar de uma conhecida instituição pública no centro da cidade). Constitui-se uma escola pública diametralmente oposta da escola de João, como pode ser verificado nos quatro fragmentos a seguir, novamente com grifos meus:

Fragmento 5 (inicial)

Escrever este relato para mim foi algo que me tocou bastante. Nossa! A visita à escola foi algo fora do comum, amei. Esse resgate para mim foi muito especial, pude reviver momentos muito especiais e visitar lugares tão marcantes para mim durante um período muito feliz da minha vida, foi fantástico. Muitas memórias vieram à tona.

Fragmento 6

Eu sempre fui de participar e gostava de participar de tudo, estava sempre engajada em algum projeto, teatro, jogos escolares, xadrez, grêmio 
estudantil, jornalzinho da escola. Ah! Pude me lembrar dos meus diários, naquele tempo eu escrevia diário e às vezes gerava tanta confusão na minha casa, pois minha mãe só descobria minhas coisas quando ela pegava meu diário, aí já era...

Fragmento 7

Afinal minha turma do primeiro ano foi desarticulada e dividida para que não fosse mais o terror nos próximos anos. Durante a exposição de fotos na turma de estágio eu falei: Deus me livre de pegar uma turma como a minha, bom, naquela época, é claro que eu não imaginava o que queria fazer da minha vida. Acabei seguindo um curso na área de saúde por influência da minha mãe, mas isso ficará para um próximo relato.

Fragmento 8 (final)

Gostaria apenas de não mais me estender e concluir dizendo que foi maravilhosa a experiência da visita à escola e da fotobiografia, e que um registro mais detalhado das fotos e de alguns comentários estará disponivel no meu portfólio.

No fragmento 5, abrindo o relato, podemos notar a voz de autora, posicionada como professora em formação, comentando como foi tocante escrever o relato; no fragmento 6, a voz de personagem/escritora remete a práticas de letramento da época escolar (projeto, teatro, jornalzinho da escola, diário), inclusive há conflitos familiares devido ao diário revelador. No fragmento 6 se constitui a voz de personagem de estudante engajada, pois Ana "gostava de participar de tudo". Nesses dizeres, configura-se uma escola que diz sim à vida (FREIRE, 1994), vibrante, onde a participação e o diálogo são possíveis - enfim, as instâncias enunciativas configuram a escola como agência de letramento, em oposição àquela configurada no texto de João, a escola que emudece.

No fragmento 7 constitui-se tanto a voz de autora/professora em formação (no presente), como também a voz de personagem/professora profissional (imaginada no futuro), pois nos dizeres "Durante a exposição de fotos na turma de estágio eu falei: Deus me livre de pegar uma turma como a minha”, a docente é claramente sinalizada, avaliando um possível contexto profissional complexo. Ainda nesse fragmento, podemos perceber, ao indicar um caminho profissional, a voz de personagem/mãe incentivando os estudos da filha, que segue na área de saúde, posteriormente optando por um caminho nas Letras. No fragmento final, novamente constitui-se voz de autoral professora em formação no trecho "foi maravilhosa a experiência da visita à 
escola e da fotobiografia", como também na referência ao portfólio, sinalizando engajamento com narrativas de formação. Enfim, constata-se que é no início e no final dos dois relatos que as instâncias enunciativas assumem, como voz predominante, axiológica, a posição autoral/professor em formaçăo, assumindo responsabilidade pelo que é dito, comentando e avaliando os enunciados.

Por fim, em resposta à questão inicial - quais as principais vozes enunciativas que emergem em relatos autobiográficos desencadeados por fotobiografias escolares e o que dizem sobre si e sobre a escola - é possível verificar que nos fragmentos acima mencionados ecoam: (i) vozes de personagens/alheias, situadas no passado - um professor de português e uma mãe, vozes de incentivo; (ii) vozes de personagens/de si mesmo no passado, constituindo a voz de estudante do Ensino Médio, de escritora e de vestibulando/universitário, sinalizando tensões e práticas de letramento na escola, como também uma voz de personagem/de si mesmo no futuro, uma profissional do ensino preocupada com seu agir docente; e (iii) a voz de autor, situada no presente e constituída como professor/a em formação, sinalizando tensōes e reconfiguraçōes emergentes. A escola pública ora é configurada como uma agência de letramento - engajada, acolhedora, estimulando inclusão e participação, ora como uma instituição caótica, descompromissada e hostil.

Sobre a questão das práticas linguageiras situadas (isto é, os textos) como instrumentos para o desenvolvimento humano, acredito que no módulo inicial da disciplina de Estágio Supervisionado houve envolvimento existencial dos graduandos - e na distribuição de vozes orquestradas em relatos autobiográficos, ressoam vozes de personagens e voz de autor empírico, indiciando, arrisco dizer, reconfiguraçōes em termos de identidade e gênero profissional docente. Em suma, gostaria de revisitar a epígrafe, sublinhando "que as palavras são tecidas a partir de uma multidão de fios ideológicos e servem de trama a todas as relaçóes sociais em todos os domínios" (BAKHTIN; VOLOSHINOV, 1999, p. 41). Nesses termos, ao refletir sobre as palavras de formandos no estágio supervisionado em Letras Estrangeiras e levando em conta as atividades plurigenéricas e pertencimentos múltiplos (CLOT, 2007), percebo que todos nós conseguimos sutilmente tecer e redimensionar gênero e identidade profissional, reescrevendo(-nos) e coproduzindo novas e delicadas tramas que podem vir a sustentar um agir docente renovado. 


\section{Considerações finais}

Como já dito na introdução, buscando entrelaçar o gênero relato autobiográfico ao gênero profissional e obter o envolvimento existencial dos formandos na experiência de ser autor e de ser leitor, mediei, em um curso de licenciatura em Letras, uma prática de letramento alicerçada em fotobiografias realizadas na própria escola básica. É relevante apresentar algumas considerações apontadas por este trabalho, a saber: a universidade como lugar privilegiado para o narrar-se; a pluralidade e instabilidade de vozes ecoando na sala de aula do ensino superior; que práticas e posturas socioprofissionais podem ser renovadas por meio da escrita, sugerindo uma convergência entre o escrever $\mathrm{e}$ o refazer(-se); finalmente, que reposicionamentos constituem e são constituídos pela língua(gem), sinalizados pelas vozes de outros e de si, inscrevendo reconfiguraçōes identitárias singulares e revitalizando o gênero profissional, sempre em construção. Em relação à identidade docente, outras questōes intrigantes serão discutidas futuramente, focalizando as vozes sociais que também ecoam em textos dos formandos, entre outros aspectos.

Retomando a perspectiva do professor como agente de letramento, conforme Kleiman $(2006 ; 2011)$, vale lembrar que foram colocados em cena os três elementos relevantes para a construção identitária no processo de socialização profissional - a agência humana, a agência institucional e a prática situada da escrita, levando em conta a heterogeneidade das experiências de letramento e trajetórias de formação. Concluindo, este trabalho visibiliza entrecruzamentos da pluralidade da vida social com a singularidade de histórias discursivas em um contexto de formação inicial, interiluminando a vida na sala de aula no Ensino Superior. Nos fragmentos analisados constata-se que os professores em formação, ao escreverem suas histórias vividas na escola, identificam-se por meio de vozes enunciativas materializadas em dois relatos autobiográficos, como também se inscrevem em uma narrativa social mais ampla sobre práticas de letramento e formação identitária que busca dar conta, muito provisoriamente, da vida nos mundos da escola, da universidade, do trabalho e da linguagem. 


\section{Referências}

BAKHTIN, M. Estética da criação verbal. 5. ed. Tradução de Paulo Bezerra. São Paulo: WMF; Martins Fontes, 2010.

BAKHTIN, M.; VOLOSHINOV, V. N. Marxismo e filosofia da linguagem: problemas fundamentais do método sociológico na ciência da linguagem. Tradução de Michel Lahud e Yara Frateschi Vieira. São Paulo: Hucitec, 1999.

BALLOUSSIER, A. V. Cineasta de 22 anos ganha prêmio com curta sobre vestibular. Disponível em: <http://www1.folha.uol.com.br/folhateen/992184-cineasta-de22-anos-ganha-premio-com-curta-sobre-vestibular.shtml>. Acesso em: 19 out. 2011.

BARTON, D.; HAMILTON, M. Literacy practices. In: BARTON, D.; HAMILTON, M.; IVANIC, R. (Org.). Situated Literacies: Reading and Writing in Context. London; New York: Routledge, 2000. p. 7-15.

BARTON, D.; HAMILTON, M.; IVANIC, R. (Org.). Situated Literacies: Reading and Writing in Context. London; New York: Routledge, 2000.

BAUMAN, Z. Identidade: entrevista a Benedetto Vecchi. Rio de Janeiro: Jorge Zahar, 2005.

BOHN, H. I. A formação do professor de línguas: a construção de uma identidade profissional. Revista Investigações - Linguística e Teoria Literária, Recife, v. 17 , n. 2, p. 97-113, jul. 2004.

BRONCKART, J. P. Atividade de linguagem, discurso e desenvolvimento humano. Trad. Anna Rachel Machado e Maria de Lourdes Meirelles Matêncio. Campinas: Mercado de Letras, 2006.

BRONCKART, J. P. Atividade de linguagem, textos e discursos: por um interacionismo sociodiscursivo. São Paulo: Educ, 1999.

BRONCKART, J. P. O agir nos discursos: das concepções teóricas às concepções dos trabalhadores. Trad.: Anna Rachel Machado; Maria de Lourdes Meirelles Matêncio. Campinas: Mercado de Letras, 2008.

BUENO, L. A construção de representaçôes sobre o trabalho docente: o papel do estágio. 2007. 205 f. Tese (Doutorado em Linguística Aplicada) - Linguística Aplicada e Estudos da Linguagem, Pontifícia Universidade Católica de São Paulo, São Paulo, 2007.

CLOT, Y. A função psicológica do trabalho. Tradução de Adail Sobral. 2. ed. Petrópolis: Vozes, 2007.

CONNELLY, F. M.; CLANDININ, D. J. Shaping a Professional Identity: Stories of Educational Practice. New York: Teachers College Press, 1999. 
DENZIN, N. K.; LINCOLN, Y. S. (Org.). O planejamento da pesquisa qualitativa: teorias e abordagens. Trad. Sandra Regina Netz. 2. ed. Porto Alegre: Artmed, 2007.

DIAS, S. M. A. O blog reflexivo no processo de letramento e formação de professores de língua inglesa. In: MEDRADO, B. P.; REICHMANN, C. L. (Org.) Práticas de formação de professores de língua inglesa [Inédito. Título provisório].

DUBAR, C. A socialização: construção de identidades sociais e profissionais. São Paulo: Martins Fontes, 2005.

ELBAZ-LUWISCH, F. Teachers' Voices: Storytelling and Possibility. Greenwich (CT): Information Age Publishing, 2005.

FARACO, C. A. Linguagem \& diálogo: as ideias linguísticas do Círculo de Bakhtin. São Paulo: Parábola Editorial, 2009.

FARACO, C. A. O estatuto da análise e da interpretação dos textos no quadro do círculo de Bakhtin. In: GUIMARÃES, A. M. de M.; MACHADO, A. R.; COUTINHO, A. (Org.). O interacionismo sociodiscursivo: questôes epistemológicas e metodológicas. Campinas: Mercado de Letras, 2007. p. 43-50.

FREIRE, P. Professora sim, tia não: cartas a quem ousa ensinar. 5. ed. São Paulo: Olho D’Água, 1994.

GUIMARÃES SILVA, J. Q.; MATÊNCIO, M. De L. M. Referência pessoal e jogo interlocutivo: efeitos identitários. In: KLEIMAN, A. B.; MATÊNCIO, M. De L. M. (Org.). Letramento e formação de professores: práticas discursivas, representações e construção do saber. São Paulo: Mercado de Letras, 2005. p. 245-266.

HALL, S. Da diáspora: identidades e mediações culturais. Belo Horizonte: Editora UFMG, 2003.

HEATH, S. B. Ways with words, Language, Life and Work in Communities and Classrooms. Cambridge (UK): Cambridge University Press, 1983.

JOSSO, M.-C. Experiências de vida e formação. São Paulo: Cortez, 2004.

KLEIMAN, A. B. (Org.). Os significados do letramento: uma nova perspectiva sobre as práticas sociais da escrita. Campinas: Mercado de Letras, 1995.

KLEIMAN, A. B. Letramento crítico: a escrita na formação profissional. In: CONGRESSO BRASILEIRO DE LINGUÍSTICA APLICADA, 9., 25-28 jul. 2011, Rio de Janeiro. Caderno de resumos... Rio de Janeiro: UFRJ, 2011. Disponível em: <http://www.alab.org.br/images/stories/alab/caderno\%20de\% 20 resumos\%20ix\%20cbla\%20a4\%20com\%20errata.pdf>. Acesso em: 19 out. 2011 . 
KLEIMAN, A. B. Letramento e suas implicações para o ensino de língua materna. Revista Signo, Santa Cruz do Sul, v. 32, n. 53, p. 1-25, 2007.

KLEIMAN, A. B; MATÊNCIO, M. de L. M. (Org.). Letramento e formação de professores: práticas discursivas, representaçōes e construção do saber. São Paulo: Mercado de Letras, 2005.

KLEIMAN, A. B. Processos identitários na formação profissional: o professor como agente de letramento. In: CORREA, M.; BOCH, F. (Org.). Ensino de lingua: representação e letramento. São Paulo: Mercado de Letras, 2006. p. 75-91.

LÜDKE, M. Universidade, escola de educação básica e o problema do estágio na formação de professores. Formação Docente, Belo Horizonte, v. 1, n. 1, p. 95-108, ago.-dez. 2009. Acesso em: 23 out. 2011. Disponível em: <http://formacaodocente. autenticaeditora.com.br/artigo/exibir/1/5/1>. Acesso em: 19 out. 2011.

MACHADO, A. R. (Org.). O ensino como trabalho: uma abordagem discursiva. Londrina: EDUEL, 2004.

MACHADO, A. R.; LOUSADA, E. G.; FERREIRA, A. D’O. (Org.). O professor e seu trabalho: a linguagem revelando práticas docentes. Campinas, SP: Mercado de Letras, 2011.

MEDRADO, B. P. Compreensão da docência como trabalho: reflexões e pesquisas na/da Linguística Aplicada. In: MEDRADO, B. P.; PÉREZ, M. (Org.). Leituras do agir docente: a atividade educacional à luz da perspectiva interacionista sociodiscursiva. São Paulo: Pontes, 2011. p. 21-36.

MOITA LOPES, L. P. Da aplicação da Linguística à Linguística Aplicada Indisciplinar. In: PEREIRA, R. C.; ROCA, P.(Org.). Linguistica Aplicada: um caminho com muitos acessos. São Paulo: Contexto, 2009. p. 11-24.

MOTT-FERNANDEZ, C.; CRISTÓVÃO, V. L. L. A tessitura do gênero profissional docente revelada em narrativas de aprendizagem. In: CRISTŌVĀO, V. L. L. (Org.). Estudos da linguagem à luz do Interacionismo Sociodiscursivo. Londrina: Eduel, 2008. p. 145-161.

NÓVOA, A. (Org.). Vidas de professores. Porto: Porto, 1992.

OLIVEIRA, M. do S. Gêneros textuais e letramento. Revista Brasileira de Linguistica Aplicada, Belo Horizonte, v. 10, n. 2, p. 325-345, 2010.

OLIVEIRA, M. do S.; KLEIMAN, A. B. Letramentos múltiplos: agentes, práticas, representações. Natal: EDUFRN, 2008.

PEREIRA, M. de A. Amei essa aula! - um estudo interacionista sociodiscursivo sobre vozes em diários dialogados de professoras de língua inglesa. 2011. 216 f. Dissertação (Mestrado em Linguística) - Programa de Pós-Graduação em Linguística, Universidade Federal da Paraíba, João Pessoa, 2011. 
PEREIRA, R. C. A constituição social e psicológica do texto escrito. In: PEREIRA, R. C.; ROCA, P. (Org.). Linguística Aplicada: um caminho com muitos acessos. São Paulo: Contexto, 2009. p. 113-142.

PÉREZ, M. Com a palavra, o professor: vozes e representaçôes docentes à luz do ISD. 2009. 153 f. Dissertação (Mestrado em Linguística) - Programa de PósGraduação em Linguística, Universidade Federal da Paraíba, João Pessoa, 2009. REICHMANN, C. L. Práticas de letramento e (form)ação de professores de língua estrangeira: vozes da escola. In: CONGRESSO BRASILEIRO DE LINGUÍSTICA APLICADA, 9., 25-28 jul. 2011, Rio de Janeiro. Caderno de resumos... Rio de Janeiro: UFRJ, 2011. Disponível em: <http://www.alab.org.br/images/stories/ alab/caderno\%20de $\% 20$ resumos $\% 20 \mathrm{ix} \% 20 \mathrm{cbla} \% 20 \mathrm{a} 4 \% 20$ com $\% 20$ errata.pdf >. Acesso em: 19 out. 2011.

RODRIGUES, M. A. N. As (re) configuraçôes sobre o trabalho docente em relatórios de estágio. 2011. 216 f. Tese (Doutorado em Linguística) - Programa de PósGraduação em Linguística, Universidade Federal da Paraíba, João Pessoa, 2011. ROMERO, T. R. de S. Linguagem e memória no construir de futuros professores de inglês. Revista Brasileira de Linguistica Aplicada, v. 8, n. 2, p. 401-420, 2008. SCRIBNER, S.; COLE, M. The Psychology of Literacy. Cambridge (MA): Harvard University Press, 1981.

STREET, B. V. Cross-Cultural Approaches to Literacy. Cambridge (UK): Cambridge University Press, 1993.

STREET, B. V. Literacy in Theory and Practice. Cambridge (UK): Cambridge University Press, 1984.

STREET, B. V. What's "new" in New Literacy Studies? Critical Approaches to Literacy in Theory and Practice. Current Issues in Comparative Education, New York, v. 5, n. 2, p. 77-91, 2003.

STUTZ, L. Modelos didáticos, sequências didáticas, socialização de diários e autoconfrontação: instrumentos para a formação inicial de professores de inglês. 2011. 343 f. Tese (Doutorado em Estudos da Linguagem) - Universidade Estadual de Londrina, Londrina, 2011.

TÁPIAS-OLIVEIRA, E. M. Construção identitária profissional no Ensino Superior: prática diarista e formação do professor. 2006. $213 \mathrm{f}$. Tese (Doutorado em Linguística Aplicada) - Instituto de Estudos da Linguagem, Universidade Estadual de Campinas, Campinas, 2006.

VÓVIO, C. L.; DE GRANDE, P. B. O que dizem as educadoras sobre si: construções identitárias e formação docente. In: VÓVIO, C. L.; SITO, L.; DE GRANDE, P. B. (Org.). Letramentos: rupturas, deslocamentos e repercussões de pesquisas em LA. Campinas: Mercado de Letras, 2010. p. 51-70. 


\section{Anexo-Relatos autobiográficos}

Ana: Relato sobre a escola

Escrever esse relato para mim foi algo que me tocou bastante. Nossa! A visita à escola foi algo fora do comum, amei. Esse resgate para mim foi muito especial, pude reviver momentos muito especiais, e poder visitar lugares tão marcantes para mim durante um período muito feliz da minha vida, foi fantástico. Muitas memórias vieram à tona.

Com essa visita pude perceber que a grande maioria das minhas lembranças, se não todas, foram muito felizes. Naquela época, eu era feliz e sabia disso. Convivendo com tantas perdas durante a minha vida, criei o hábito de me aproveitar das pessoas, ou melhor, aproveitar os momentos felizes que passo com elas. De fazer com que elas percebam que são especiais para mim e que eu as amo.

Durante os três anos que estudei em L eu tive o privilégio de conviver com muitas pessoas especiais, e que hoje eu já não tenho. Por um lado, ao fazer a fotobiografia, eu pude me lembrar que eu tinha algumas fotos de quando eu havia estudado lá, resolvi, então, procurar essas fotos antigas e aí que eu não aguentei mais, senti tantas saudades das minhas amigas e do meu irmão que hoje já volto ao nosso lar. Naquela época ele ainda estava conosco, sinto muita falta dele, pois éramos muito unidos e vivíamos juntos (unha e cutícula).

Pude relembrar amigas especiais e com algumas delas tenho contato até hoje, muito esporadicamente, um amigo especial que morava em $\mathrm{F}$ e que na ocasião só nos correspondíamos através de cartas. Tenho todas as cartas dele até hoje. Tenho foto dos projetos e feira de ciências na escola.

Eu sempre fui de participar e gostava de participar de tudo, estava sempre engajada em algum projeto, teatro, jogos escolares, xadrez, grêmio estudantil, jornalzinho da escola. Ah! Pude me lembrar dos meus diários, naquele tempo eu escrevia diário e às vezes gerava tanta confusão na minha casa, pois minha mãe só descobria minhas coisas quando ela pegava o meu diário, aí já era, eu já estava frita mesmo, e só me vinha sermão. Sinto saudades de tudo isso!

Bom, agora falando um pouco sobre o meu momento como aluna, isso também é legal, estudei numa turma que era o horror da escola " 105 ", bem eu acho que era uma boa aluna, afinal respeitava meus professores e sempre tive um bom relacionamento com eles. Geralmente, já estava 
passada por média em todas as disciplinas, já no $3^{\circ}$ bimestre, então, no quarto bimestre era só gazear, conversar com minhas amigas, ir para as festinhas, fugir da escola, paquerar, essas coisas... Que depois minha mãe descobria no diário e só faltava me matar.

Durante as aulas eu prestava atenção, sentava no meio da classe assim podia transitar e fazer amizade com todos os colegas, tanto os "CDFs" que sentavam na frente da sala, quanto à "turma do fundão" que eram tidos como os bagunceiros. Vale ressaltar que na turma do primeiro ano, não tinha isso, pois todos éramos umas pestes, mas no segundo e terceiro ano, isso já funcionava. Afinal minha turma do primeiro ano foi desarticulada e dividida, para que não fosse mais o terror para os próximos anos. Durante a exposição de fotos na turma de estágio eu falei: "Deus me livre de pegar uma turma como a minha", bom, naquela época, é claro que eu não imaginava o que queria fazer da minha vida. Acabei seguindo um curso na área de saúde por influência da minha mãe, mas isso fica para um próximo relato.

Gostaria apenas de não mais me estender e concluir dizendo que foi maravilhosa a experiência de visita à escola e da fotobiografia e que um registro mais detalhado das fotos e de alguns comentários estará disponível no meu portfólio.

João: Reflexão sobre minha memória escolar

Quando tirei as fotos na visita à escola na qual estudei durante o ensino médio, tive uma breve lembrança do tempo que vivi por lá e pouca coisa me veio à cabeça no tocante à memória escolar; porém no momento em que apresentei as fotos para a turma, tive uma visão melhor da minha vida escolar e pude compartilhar o que pareceu um pouco diferente dos demais. Achei interessante ressaltar detalhadamente como na verdade funciona o ensino nas escolas públicas, os problemas encontrados nelas, principalmente problemas envolvendo segurança, falta de professores, falta de compromisso por parte dos diretores, e todos envolvidos no processo de educação. Uma das memórias mais marcantes desse período está ligada aos incentivos do professor $\mathrm{H}$, um ex-aluno dessa mesma escola, que dava a melhor aula de português, sempre conscientizando a turma de não deixar de estudar, a fim de obter um futuro melhor. Uma outra memória marcante, essa não muito boa no sentido de construir algo concreto e positivo, foi a das noites de sexta-feira, quando nos reuníamos com 
professores e algumas vezes bebíamos após as aulas conversando sobre assuntos da semana, etc.; mas toda aquela atmosfera caótica por outro lado, me instigava a estudar mais, pois sabia que passar no vestibular não seria algo fácil. Não tenho lembrança de que alguém daquela época tivesse passado no vestibular, apenas um amigo conseguiu entrar num seminário teológico de nível superior e isso alguns anos depois de terminarmos juntos. As mudanças na estrutura da escola foram poucas; a entrada, como dissera antes, foi modificada por um corredor que liga o portão de entrada até a diretoria, algumas salas em péssimas condições de funcionamento, ventiladores quebrados, carteiras quebradas... não é fácil resolver esses problemas porque são os próprios alunos que deterioram a escola, quebram os banheiros e pixam as paredes; acho que esses problemas têm relação com a construção de identidade de cada indivíduo, ou seja, problemas sociais, familiares e que pouco será resolvido por educadores. Hoje sei que as pedras encontradas no caminho serviram de montanha, onde eu pude subir e ver a vida através de uma outra perspectiva.

Recebido em 03/01/2012. Aprovado em 08/03/2012. 